Article

\title{
Frozen Microemulsions for MAPLE Immobilization of Lipase
}

\author{
Valeria Califano ${ }^{1}$, Francesco Bloisi ${ }^{2, *}$ (1) , Giuseppe Perretta ${ }^{1}$, Antonio Aronne ${ }^{3}$, \\ Giovanni Ausanio ${ }^{2}$, Aniello Costantini ${ }^{3}$ and Luciano Vicari ${ }^{2}$ (iD \\ 1 Istituto Motori-CNR, via G. Marconi 8, 80125 Napoli, Italy; v.califano@im.cnr.it (V.C.); \\ g.perretta@im.cnr.it (G.P.) \\ 2 CNR-SPIN and Department of Physics "Ettore Pancini", University of Naples Federico II, \\ Piazzale V. Tecchio 80, 80125 Napoli, Italy; ausanio@unina.it (G.A.); vicari@unina.it (L.V.) \\ 3 Department of Chemical Engineering, Materials and Industrial Production, University of Naples Federico II, \\ Piazzale V. Tecchio 80, 80125 Napoli, Italy; anaronne@unina.it (A.A.); anicosta@unina.it (A.C.) \\ * Correspondence: bloisi@unina.it; Tel.: +39-081-768-2585
}

Received: 21 September 2017; Accepted: 27 November 2017; Published: 5 December 2017

\begin{abstract}
Candida rugosa lipase (CRL) was deposited by matrix assisted pulsed laser evaporation (MAPLE) in order to immobilize the enzyme with a preserved native conformation, which ensures its catalytic functionality. For this purpose, the composition of the MAPLE target was optimized by adding the oil phase pentane to a water solution of the amino acid 3-(3,4-dihydroxyphenyl)-2-methyl-L-alanine (m-DOPA), giving a target formed by a frozen water-lipase-pentane microemulsion. Fourier transform infrared (FTIR) spectroscopy and atomic force microscopy (AFM) were used to investigate the structure of MAPLE deposited lipase films. FTIR deconvolution of amide I band indicated a reduction of unfolding and aggregation, i.e., a better preserved lipase secondary structure in the sample deposited from the frozen microemulsion target. AFM images highlighted the absence of big aggregates on the surface of the sample. The functionality of the immobilized enzyme to promote transesterification was determined by thin layer chromatography, resulting in a modified specificity.
\end{abstract}

Keywords: MAPLE; microemulsion; lipase; thin film; enzyme immobilization

\section{Introduction}

Lipases (E.C.3.1.1.3) are ubiquitous enzymes able to catalyze reactions of large industrial interest, such as hydrolysis, esterification and transesterification of long-chain acylglycerides. In particular, the enzymatic transesterification of vegetable oil into biodiesel allows treating raw materials with high content of free fatty acids (i.e., waste fried oil), enabling the use of low quality, reused, and inedible oils without a negative impact on the environment [1]. The widespread application of lipase in industry, however, is inhibited because milder, eco-friendly, highly active, and selective enzymatic catalysis is not competitive with chemical catalysis. This is due, on the one hand, to the lack of operational stability (low stability to temperature and $\mathrm{pH}$, loss of catalytic activity after one cycle of reaction), and on the other to difficult recovery and recycle of the enzyme [2-4]. These aspects are fundamental for industrial applications as they reduce process costs, offsetting the high production costs of enzymatic catalysts. Immobilizing enzymes on insoluble supports can address this issues [5]. Enzymatic immobilization allows combining the advantages of heterogeneous catalysis to an increased stability and sometimes increased activity [6] of the enzyme. It is therefore possible to facilitate the recovery and reuse of the catalyst and its separation from the reaction medium, lowering protein contamination of the reaction products. Immobilization often results in increased stability toward denaturation induced by heat, organic solvents, or inhibitors. This enhancement of the enzyme stability 
depends on the type of support and the technique used for the immobilization and can be due to a different microenvironment to which the immobilized enzyme is exposed and/or an enhanced rigidity of the immobilized enzyme [7,8]. Another important aspect, relevant for enzymes such as lipases (to which is often required to work in organic solvents), is that their immobilization may allow the enzyme to exert its catalytic activity in environments fundamentally different from the physiological one, i.e., in a non-aqueous solvents [3].

Matrix assisted pulsed laser evaporation (MAPLE) is a pulsed laser technique for thin film deposition, in which the target is composed of a frozen solvent (the matrix) containing a low volume fraction of the material to be deposited (the guest material). The matrix is a volatile, light absorbing solvent. When a laser beam impacts the target, droplets of both the volatile solvent and the solute are ejected away from the target. A vacuum system pumps away the matrix molecules, while the guest material deposits onto the substrate. The matrix absorbs most of the laser radiation giving a softer ejection mechanism with respect to pulsed laser deposition (PLD), hence transferring delicate molecules from the target to the substrate in undamaged form [9-11]. Due to such attributes, the MAPLE technique has been successfully used to deposit several proteins in an undamaged and functional form [12-15]. However, the MAPLE deposition of lipase is a sensitive issue, since lipases are unique enzymes in that most of them, including Candida rugosa lipase, require interfacial activation for full catalytic performance [16]. Actually, since lipids are water insoluble, lipases act on emulsified systems. Upon adsorption at a hydrophobic/hydrophilic interface, lipase undergoes a conformational change from the inactive to the active conformation. This change is promoted by the movement of a helical loop from the "closed" form in which the catalytic site is inaccessible to the "open" active one. During the immobilization procedure the mechanism of interfacial activation must be preserved and lipase is preferably to be obtained in the "open-lid" conformation, known to be more active [17-20].

Solvent assisted techniques for lipase immobilization affect its conformation by both the nature of the substrate and the adsorption conditions (i.e., $\mathrm{pH}$ of the solution). Benefits of using MAPLE for lipase immobilization include independence of lipase conformation on enzyme/support interaction, dry deposition allowing the use water-incompatible supports, and the possibility of tailoring lipase conformation in solution. Candida rugosa Lipase (CRL) films were already obtained by MAPLE using a water matrix [21], but conformational analysis of the obtained films pointed out an important protein unfolding and aggregation/self-association.

In this work, CRL was deposited by MAPLE improving the matrix composition by adding $\mathrm{m}$-DOPA and pentane to the water matrix to obtain lipase films in which the secondary structure of the enzyme was better preserved. We show that the addition of an oil phase to the MAPLE target led to a better preservation of the protein secondary structure. Pentane was intended to induce lid opening, stabilizing the active conformation of lipase. Immobilization of lipase in the active form was immobilized by adsorption on a hydrophobic support favoring the open form of lipase in solution by varying the medium conditions [22].

m-DOPA (3-(3,4-dihydroxyphenyl)-2-methyl-L-alanine) is an analogous of L-DOPA (3,4-dihydroxyphenyl-L-alanine) with a methyl group added. L-DOPA is an unusual amino-acid residue found in the adhesive protein secreted by mussels and responsible for mussel fouling on a variety of surfaces [23]. The catechol side chain of L-DOPA is thought to be responsible for the adhesive role of these proteins. The use of MAPLE for the deposition of m-DOPA was already discussed for improving polyethylene glycol (PEG) adhesion in anti-biofouling applications [24]. m-DOPA was added to accomplish three roles: (1) to absorb the laser radiation, reducing the risk of photochemical damage to the protein; (2) to protect lipase against unfolding/aggregation that can occur during drying in plume expansion [25]; and (3) to improve adhesion of the protein to the substrate. Actually, this aminoacid adheres to various surfaces via different types of interactions, including hydrogen bonds, metal coordination, electrostatic interaction, and so on [26]. It can bind proteins with either weak interaction such as hydrogen bonding or with covalent bonding [27], thus creating a bridge between the bound polypeptide and the grafted substrate. 


\section{Results and Discussion}

The MAPLE deposition parameters are reported in Table 1.

The choice of the laser wavelength was set by the need of inducing as little damage as possible to the protein, since lipase has a large absorption band, centered at $280 \mathrm{~nm}$ [28], in the UV region normally used for MAPLE deposition and a N-H stretching vibration absorption in the IR region used for resonant infrared MAPLE (RIR-MAPLE, $2900 \mathrm{~nm}$ ) [29]. Our focus was the deposition of lipase with preserved tertiary structure, since in catalytic applications obtaining a smooth deposition is not essential. This suggested us to select a small substrate to target distance in order to maximize the deposition yield.

Table 1. Matrix assisted pulsed laser evaporation (MAPLE) deposition parameters.

\begin{tabular}{cc}
\hline Parameter & Value \\
\hline Laser wavelength & $1064 \mathrm{~nm}$ \\
Laser pulse energy & $526-410 \mathrm{~mJ} /$ pulse \\
Pulse duration & $7 \mathrm{~ns}$ \\
Pulse repetition rate & $4 \mathrm{~Hz}$ \\
Number of pulses & 23,000 \\
Target-substrate distance & $9 \mathrm{~mm}$ \\
Incidence angle & $45^{\circ}$ \\
Chamber pressure during deposition & $10^{-4} \mathrm{~Pa}$ \\
Substrate & $\mathrm{KBr}$ \\
Target temperature & $-123^{\circ} \mathrm{C}$ \\
Substrate temperature & $25^{\circ} \mathrm{C}$ \\
Target matrix & distilled water \\
\hline
\end{tabular}

Samples were obtained by varying the composition of the target solution, adding the excipient m-DOPA and the apolar solvent pentane to the lipase/water matrix system. The target composition and laser pulse energy used for each deposition are reported in Table 2. The pulse energy used corresponded to the minimum value allowing target evaporation. One of these samples, M-CRL1, was already characterized in a previous work [21].

Table 2. Target composition of MAPLE deposited samples.

\begin{tabular}{ccccc}
\hline Sample & \multicolumn{3}{c}{ Target Composition } & Pulse Energy (mJ/Pulse) \\
\hline & Lipase & m-DOPA & Pentane & \\
M-CRL1 & $0.2 \mathrm{wt} \%$ & - & - & 526 \\
M-CRL2 & $0.18 \mathrm{wt} \%$ & $0.02 \mathrm{wt} \%$ & - & 410 \\
M-CRL3 & $0.18 \mathrm{wt} \%$ & $0.02 \mathrm{wt} \%$ & $0.5 \% v / v$ & 410 \\
\hline
\end{tabular}

m-DOPA was added because it absorbs the IR laser radiation, since the third overtone of C-H stretching of aromatic groups is located around $1064 \mathrm{~nm}$ [30], while water does not have absorption bands near that wavelength. Actually, m-DOPA lowered the ablation threshold of the target thus allowing using lower laser pulse energy, as indicated in Table 2. Furthermore, m-DOPA acts as an excipient to protect lipase from denaturation induced during plume expansion by drying [28] and improves adhesion. Pentane was added to induce lid opening and was responsible for the microemulsion formation. The addition of pentane, $0.5 \%$ in volume respect to the water, did not cause any phase separation or opalescence. Since pentane is poorly soluble in water (solubility at $25^{\circ} \mathrm{C}$ in molar fraction $x=1.2 \times 10^{-5}$ [31] vs. $x=7.8 \times 10^{-4}$ used in this work), we assume that a microemulsion was formed due to the amphiphilic nature of lipase [32]. Proteins can be said to be more interfacial active than low molecular weight surfactant [33]. The tendency of lipases (and many other proteins) to interact with hydrophobic surfaces is a consequence of the amphiphilic character of the macromolecules. The mechanism of the pentane/water/CRL microemulsion formation of this study is not known. However, a hypothesis is that in the water solution of lipase couples of open 
lid molecules may interact with each other via the large hydrophobic surface surrounding the active center, creating a hydrophobic pocket. Palomo et al. [34] in fact proposed that some lipases, including CRL, may have a specific trend to self-assemble even in diluted solutions giving bimolecular structures formed by two open lipase molecules interfacially activating each other. MAPLE deposition from a frozen microemulsion target was feasible since protein stabilized emulsions, unlike other emulsified systems, have reduced tendency to phase separation during freezing [35].

Infrared spectroscopy is a well-established technique for the conformational analysis of proteins [36] and has been used to study the secondary structure of proteins both in water solution $[37,38]$ and in the solid state $[39,40]$. Fourier transform infrared (FTIR) spectra of the three MAPLE-deposited samples, together with those of free-CRL, are reported in Figure 1a $\left(1300-1800 \mathrm{~cm}^{-1}\right.$ range) and $1 \mathrm{~b}\left(2600-4000 \mathrm{~cm}^{-1}\right.$ range), since the absorption of the various secondary structural elements of the protein backbone can be studied in these spectral regions. The spectra were normalized for the height of the band at $1655 \mathrm{~cm}^{-1}$. In Figure 1, the FTIR spectrum of free-CRL (trace d) shows four main absorption bands ascribed to the vibration modes of the protein backbone. The band in the $1600-1700 \mathrm{~cm}^{-1}$ region, the amide I absorption band, centered at $1655 \mathrm{~cm}^{-1}$, originates mainly from the $\mathrm{C}=\mathrm{O}$ stretching vibration of the peptide group, whose frequency depends on the strength of hydrogen-bonds $\mathrm{C}=\mathrm{O}-\mathrm{H}-\mathrm{N}$ and on the dipole-dipole interactions between carboxyl groups along the peptide chain. In turn, this is determined by the secondary structure adopted by the polypeptide chain and this band is therefore sensitive to the protein conformation [37]. This band consists of overlapping components representing secondary structure elements such as $\alpha$-helices, $\beta$-sheets, $\beta$-turns, and disordered structures. Several methods have been developed to estimate quantitatively the relative contributions of different types of secondary structures. Among these, second derivative spectra allow the identification of various secondary structures present in the protein. Curve fitting procedure can then be applied to calculate quantitatively the area of each component representing a type of secondary structure. The band centered at $1540 \mathrm{~cm}^{-1}$, amide II, is mainly related to the out-of-phase combination of the N-H in-plane bending and the C-N stretching vibration. This band also strongly depends on the secondary structure elements from which it originates, but the correlation structure/frequency is less straightforward. The amide III (1370-1480 $\left.\mathrm{cm}^{-1}\right)$ derives mainly from the in phase combination of the $\mathrm{N}-\mathrm{H}$ bending and the $\mathrm{C}-\mathrm{N}$ stretching vibration; due to the complexity of these contributes there is not a direct correlation between the position of this band and the protein structure. The band in the range $3420-3450 \mathrm{~cm}^{-1}$, the amide A absorption band, is due to the stretching of the N-H bond. The frequency of the amide A vibration depends on the strength of the hydrogen bond. In particular, $\mathrm{N}-\mathrm{H}$ bonds in $\alpha$-helices and $\beta$-sheets absorb around $3300 \mathrm{~cm}^{-1}$, while in random-coil structure the absorption band shifts to $3400 \mathrm{~cm}^{-1}$ [41].

By comparing the spectra of free-CRL and MAPLE deposited lipases (Figure 1), three main differences were seen: in the spectra of MAPLE deposited lipases (i) the amide I band shifted towards lower wave-numbers; on the contrary; (ii) the amide A band shifted to higher wave-numbers. Moreover, and (iii) the relative intensity of the amide II band was strongly reduced resulting partially overlapped with the amide I band for the M-CRL2 and M-CRL3. Further differences are seen in the $1300-1500 \mathrm{~cm}^{-1}$ region: in the spectra of M-CRL1 and M-CRL2, a strong band centered at $1460 \mathrm{~cm}^{-1}$ occurred, whereas in the spectrum of M-CRL3, a weaker and smoother band was seen that resembles the envelope of the two bands occurring for the free-CRL.

To ascertain that the differences observed in the spectra were not due to vibrational modes of m-DOPA, its FTIR spectrum was acquired and is showed in Figure 2, together with the spectra of lyophilized CRL and M-CRL3 for comparison. Furthermore, a mix of $1.8 \mathrm{mg}$ of CRL and $0.6 \mathrm{mg}$ of $\mathrm{m}$-DOPA (three times the amount used in the MAPLE target) diluted in $\mathrm{KBr}$ (total weight $=200 \mathrm{mg}$ ) was also examined, to see how the presence of DOPA would have influenced the spectrum of CRL, and is also reported in Figure 2. It is evident that the bands of m-DOPA were not visible in the spectra of MAPLE deposited samples, since they would have appeared as quite narrow peaks in the $1300-1550 \mathrm{~cm}^{-1}$ range, as illustrated in the spectrum of the CRL/m-DOPA mix. Furthermore, 
despite the fact that the amount of m-DOPA in the mix was thrice with respect to the MAPLE target, the displacement of its amide I band was much smaller respect to that of M-CRL3 $\left(6 \mathrm{~cm}^{-1} \mathrm{vs}\right.$. $23 \mathrm{~cm}^{-1}$ ), confirming that the differences observed in the spectra of the samples were due to the CRL conformational changes and not to the presence of m-DOPA. Finally, the spectrum that presented the major differences was the one of the sample M-CRL1, were m-DOPA was absent.

(1)

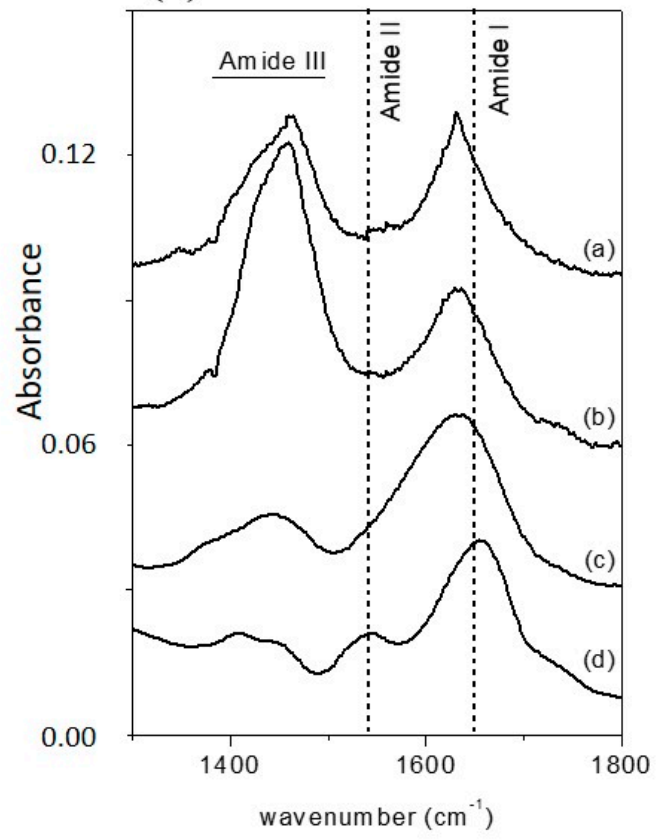

(2)

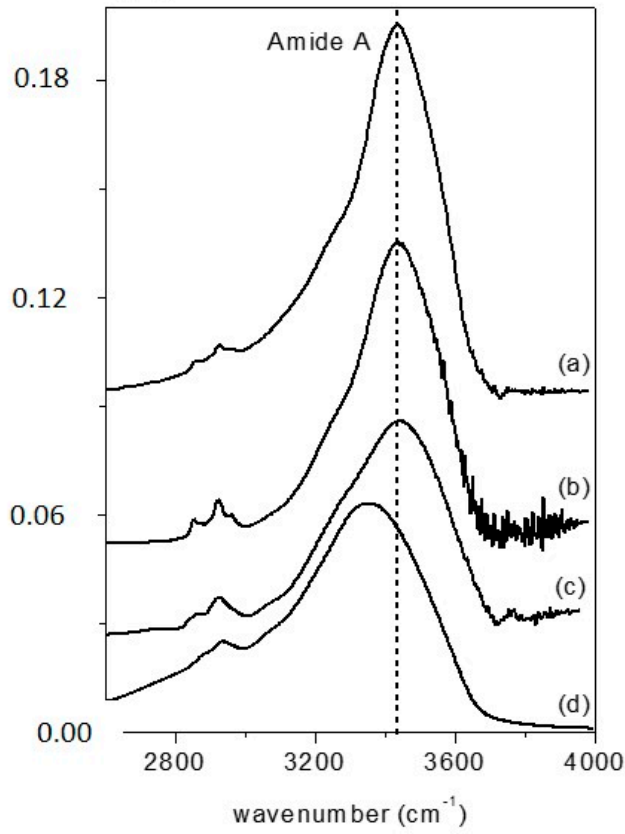

Figure 1. Fourier transform infrared (FTIR) spectra of (a) M-CRL1; (b) M-CRL2; (c) M-CRL3; and (d) free-CRL in the wavenumber range $1300-1800 \mathrm{~cm}^{-1}$ (1) and $2600-4000 \mathrm{~cm}^{-1}$ (2). The spectra were normalized to the height of amide I absorption band.

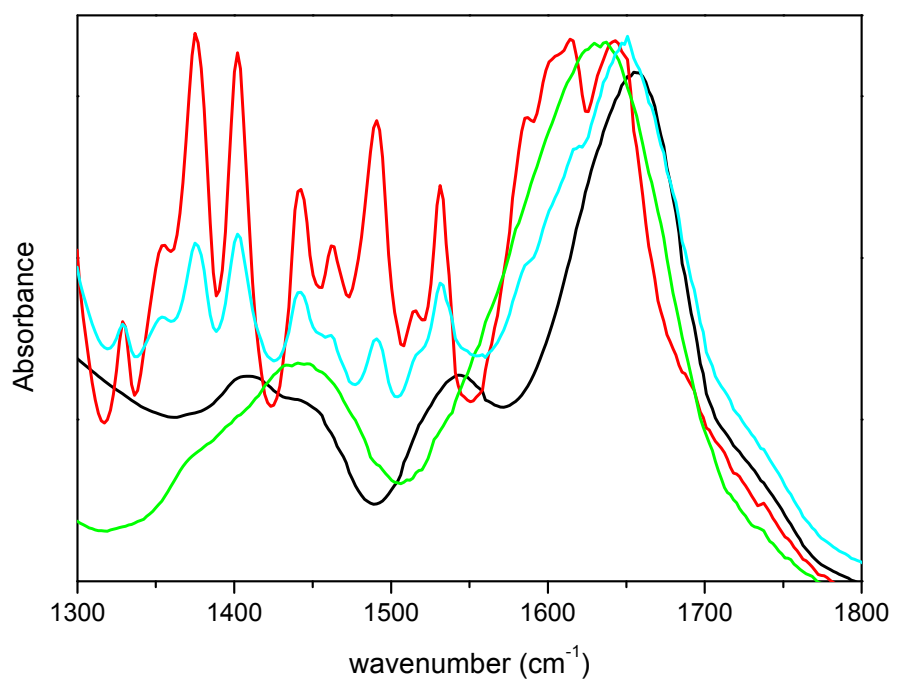

Figure 2. FTIR spectra of m-DOPA (red), free-CRL (black), M-CRL3 (green), and CRL/m-DOPA $1.8 \mathrm{mg} / 0.6 \mathrm{mg}$ diluted in $\mathrm{KBr}$ (cyan).

The displacement of the amide I band towards lower wave-numbers was already attributed to an important phenomenon of protein unfolding/aggregation [21]. From the spectra of Figure 1 it can be seen that this shift was more pronounced in M-CRL1 and M-CRL2 (about $27 \mathrm{~cm}^{-1}$ ) than in M-CRL3 
(about $20 \mathrm{~cm}^{-1}$ ). To determine the degree of unfolding, a curve fitting procedure was applied to the spectra of the three MAPLE deposited samples and compared with that of free lipase. The results are reported in Table 3 while in Figure 3 are illustrated the second derivative spectra of the amide I used as fit initial values and the best fit Gaussian components obtained for M-CRL2 (trace (b)) and M-CRL3 (trace (a)). Since in these spectra the amide I and amide II bands were partially overlapped, in the fitting procedure, the amide II was considered as a component of the amide I band. Moreover, in the spectrum of M-CRL2 the amide III band was partially overlapped with the amide II. Consequently, to avoid errors in the baseline correction, these two bands were included in the fitting procedure.

(a)

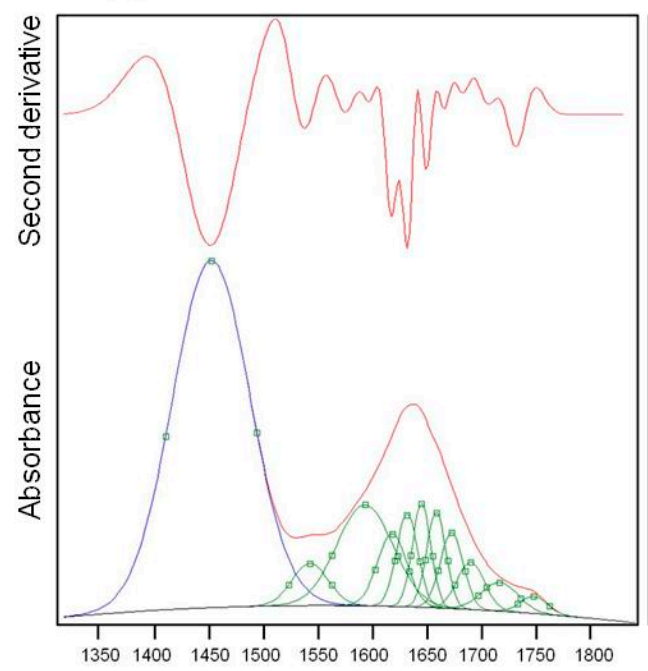

(b)

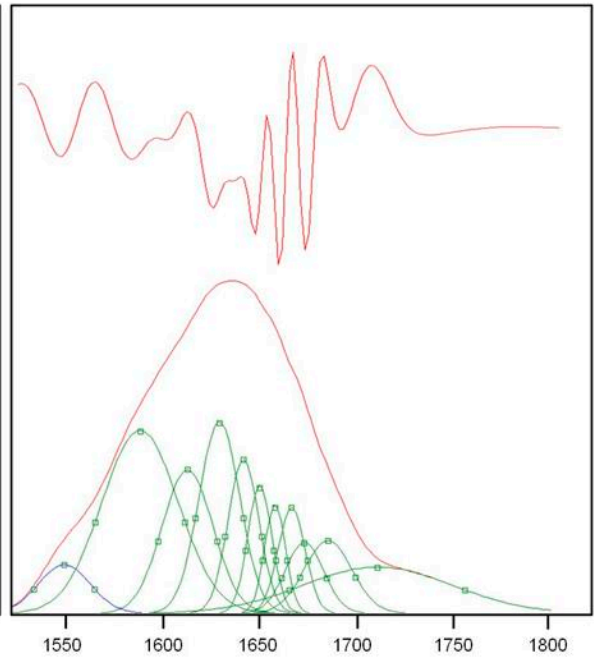

Wavenumber $\left(\mathrm{cm}^{-1}\right)$

Figure 3. Best fit Gaussian components (green) and second derivative spectra (red) of amide I of (a) M-CRL3 and (b) M-CRL2. The blue peaks belong to amide II.

Table 3. Band position $\left(\mathrm{cm}^{-1}\right)$ and assignment of the best-fit Gaussian components of the amide I band.

\begin{tabular}{|c|c|c|c|c|c|}
\hline \multirow[b]{2}{*}{ Free CRL } & \multicolumn{3}{|c|}{ Gaussian Component Position $\left(\mathrm{cm}^{-1}\right)$} & \multirow[t]{2}{*}{ Attribution } & \multirow[t]{2}{*}{ Literature Data } \\
\hline & M-CRL1 & M-CRL2 & M-CRL3 & & \\
\hline & 1566 & 1539 & 1548 & Amide II & $1530-1550[40]$ \\
\hline & 1585 & 1588 & 1587 & $\mathrm{C}=\mathrm{O}$ stretching of $\mathrm{COO}^{-}$ & $1565-1585[40]$ \\
\hline 1609 & 1618 & 1613 & 1612 & Intermolecular $\mathrm{H}$-bonded $\mathrm{C}=\mathrm{O}$ (aggregates) & $1610-1620[39]$ \\
\hline $\begin{array}{l}1623 \\
1635\end{array}$ & 1631 & 1626 & 1629 & $\beta$-sheets & $1620-1650[39]$ \\
\hline 1640 & 1642 & 1639 & 1641 & Disordered structures & $1640-1650[42]$ \\
\hline 1650 & 1650 & & 1650 & & $1650-1660[39]$ \\
\hline 1659 & 1657 & 1652 & 1658 & $\alpha$-helices & \\
\hline $\begin{array}{l}1668 \\
1676\end{array}$ & 1667 & $\begin{array}{l}1663 \\
1673\end{array}$ & $\begin{array}{l}1666 \\
1673\end{array}$ & $\beta$-turns & $1660-1690$ [39] \\
\hline 1685 & 1696 & 1687 & 1685 & B-tunrns $/ \beta$-sheets & $1680-1696[42,43]$ \\
\hline 1711 & 1738 & 1710 & 1711 & $\mathrm{C}=\mathrm{O}$ stretching of $-\mathrm{COOH}$ & \\
\hline
\end{tabular}

The Gaussian components at wavenumbers smaller than $1590 \mathrm{~cm}^{-1}$ were attributable to components of amide II band overlapping with amide I, while the component occurring in the $1580-1590 \mathrm{~cm}^{-1}$ range was due to the $\mathrm{C}=\mathrm{O}$ stretching of the $\mathrm{COO}^{-}$aspartic and glutamic acid side chain. As matter of the fact, based on the values of lipase $\mathrm{pKa}$, Asp and Glu side chains were largely deprotonated at the matrix $\mathrm{pH}(=7)$. The components at wavenumbers higher than $1610 \mathrm{~cm}^{-1} \mathrm{were}^{-}$ related to the $\mathrm{C}=\mathrm{O}$ stretching in the various conformational environment of the protein $(\alpha$-helices, $\beta$-sheets, $\beta$-turns and disordered structures, intermolecular $\beta$-strands). From the area of each of these 
components, it was possible to evaluate the percentage of the secondary structure elements for the four samples. The results are reported in Table 4.

Table 4. Percentage of the secondary structure elements.

\begin{tabular}{ccccc}
\hline Structural Element & Free-Lipase & M-CRL1 & M-CRL2 & M-CRL3 \\
\hline$\beta$-sheets & 25.4 & 14.5 & 18.1 & 23.4 \\
$\alpha$-helices & 27.2 & 21.3 & 15.6 & 15.4 \\
$\beta$-turns & 16.3 & 14.7 & 21.3 & 16.1 \\
$\beta$-turns $/ \beta$-sheets & 13.7 & 4.3 & 8.1 & 10.1 \\
Aggregates & 14.8 & 27.8 & 19.6 & 21.1 \\
Disordered & 2.6 & 17.4 & 17.3 & 13.9 \\
\hline
\end{tabular}

CRL conformation was determined by X-ray diffraction (XRD) on lipase crystals [44,45]. XRD data revealed in the CRL open conformation $30 \%$ for $\alpha$-helices and $12 \%$ for $\beta$-sheets. In this study, the content of $\alpha$-helices of free lipase was lower and that of $\beta$-sheets higher with respect to X-ray diffraction data. This is ascribable to the process of lyophilisation [46]. Proteins composed of $\alpha$-helices and mixtures of $\alpha$-helices and $\beta$-sheets have generally shown reversible conformational changes upon freeze-drying. Most commonly, a significant decrease in $\alpha$-helix content was detected, with a simultaneous increase in $\beta$-sheet formation (possibly intramolecular in nature), as occurred in the free lipase sample under study. Furthermore, the presence of intermolecular $\beta$-sheets due to aggregation was detected (14.8\% aggregates in free CRL). MAPLE deposited samples showed a decrease in the $\beta$-sheet content which was dramatic in M-CRL1 sample and attenuated going toward the M-CLR3 sample. Contextually, the content of $\alpha$-helices fell. In M-CRL1 sample the content of intramolecular aggregates was $27.8 \%$, but it fell at $19.6 \%$ in M-CRL2 sample, indicating that the addition of m-DOPA was effective in reducing the phenomenon of lipase self-association, likely by providing hydrogen bonds during the freezing of the MAPLE target and drying in plume expansion. Nevertheless, there was still a certain degree of unfolding, as testified by the high percentage of disordered structures comparable with those of M-CRL1 sample. The degree of unfolding decreased in the M-CRL3 sample, confirming that the formation of a microemulsion target was efficient in better preserving the polypeptide conformation during the MAPLE process.

This interpretation can be substantiated by the analysis of amide A band in the $3000-3700 \mathrm{~cm}^{-1}$ region. Curve fitting of the amide A band for the three MAPLE-deposited lipases was performed giving two Gaussian components for all samples (Table 5). In this region the contribute related to the $\mathrm{O}-\mathrm{H}$ stretching of water can be considered to have a little influence in the overall absorption, since it was demonstrated that the MAPLE process is effective in removing water from the deposited samples [47]. The amide A band can be considered as due to the overlapping of two components: one at about $3300 \mathrm{~cm}^{-1}$ can be related to hydrogen-bonded $\mathrm{N}-\mathrm{H}$ stretching vibrations; the second at about $3420 \mathrm{~cm}^{-1}$ can be related to vibrations of free $\mathrm{N}-\mathrm{H}$ groups of the unfolded peptide forms [41]. Hence, the displacement of amide A band toward higher wavenumber can be related with unfolding of the polypeptide backbone.

Table 5. Results of amide A Gaussian deconvolution: peak positions $\left(\mathrm{cm}^{-1}\right)$, peak area, A, and relative unfolding evaluated as percentage from the area of peak 1 assuming as a reference the value of free-CRL.

\begin{tabular}{cccc}
\hline Sample & Peak 1 Peak 2 Position $\left(\mathbf{c m}^{-\mathbf{1}}\right)$ & Peak Area A & Relative Unfolding \% \\
\hline \multirow{2}{*}{ M-CRL1 } & $3222.5 \pm 4.8$ & $5.9 \pm 0.29$ & 65 \\
& $3451.5 \pm 1.2$ & $24.0 \pm 0.29$ & 71 \\
M-CRL2 & $3251.2 \pm 6.8$ & $4.9 \pm 0.37$ & \\
& $3455.2 \pm 1.8$ & $19.8 \pm 0.37$ & 42 \\
M-CRL3 & $3322.7 \pm 8.1$ & $9.76 \pm 0.68$ & \\
& $3494.8 \pm 3.3$ & $9.97 \pm 0.67$ & 0 \\
Free-CRL & $3347 \pm 4.8$ & $16.7 \pm 0.56$ & \\
& $3502 \pm 3.6$ & $2.1 \pm 0.55$ & \\
\hline
\end{tabular}


The position of the two peaks was not the same in the four samples, since N-H vibration frequency will depend on the environment of the N-H bond. For example, the position of the hydrogen-bonded $\mathrm{N}-\mathrm{H}$ stretching vibrations depends on the strength of the hydrogen bond [48]. It is worth noting that the positions of M-CRL3 peaks were closer to free-CRL respect to the other two samples.

Since N-H and N-H-O bonds have different dipole moments, resulting in different intensities of the respective absorption bands, the area of the peak 2 was not directly correlated with the degree of unfolding of the protein, even if its value decreased going from M-CRL1 to M-CRL3.

To give a quantitative measure of the unfolding occurring in the samples, the relative unfolding was expressed as percentage from the area of peak 1 assuming as a reference the value of free-CRL (Table 5). The percentage of unfolding in M-CRL2 was even a little higher than M-CRL1, while it was reduced by 23 percentage points in M-CRL3.

Finally, the band centered at $1460 \mathrm{~cm}^{-1}$ was also strictly related to the unfolding of the protein. N-H in-plane bending mode shifted downward in frequency with $\mathrm{H}$ bond breaking [49], superimposing with the modes of amide III, giving rise to a stronger absorption band centered at $1460 \mathrm{~cm}^{-1}$ and lowering the intensity of the amide II band. The intensity of the band at $1460 \mathrm{~cm}^{-1}$ was greatly reduced in the spectrum of M-CRL3, confirming that in this sample the protein conformation was better preserved. This may be due to the combined effect of decreasing laser power and the greater conformational rigidity of lipase adsorbed on the water/oil interface. Preserving the native conformation of lipase is important for it to perform its catalytic activity.

In Figure 4, optical micrographs of M-CRL2 and M-CRL3 are shown. As displayed in Figure 4a, M-CRL2 film was formed by micrometric clusters and crystalline inclusions, some of which are evidenced by white circles. These features outline that m-DOPA was effective in absorbing the infrared laser radiation thanks to its catechol side chain, its addition to the matrix target causing the deposition of a larger mass of material at a lower laser pulse energy with respect to the sole lipase/ice target [21]. The formation of clusters is typical of the MAPLE process but does not implies that they are formed of aggregate molecules of enzyme. The formation of micrometric clusters evidenced in Figure 4 has often been observed in MAPLE deposition [24,50-52]. It depends on the explosive disintegration of the target hit by the laser that gives rise to the ejection of a mixture of vapor-phase molecules, small molecular clusters, and droplets [53]. The solvent begins to evaporate during the flight from the target, so that the solute concentration in droplets and clusters increases causing the deposition of micrometric clusters. The surface of M-CRL3 film, on the contrary, was much smoother with no visible clusters at the optical microscope, Figure $4 b$, indicating a better molecular dispersion of lipase, possibly due to its adsorption at the pentane nano-droplets of the microemulsion target.

(a)

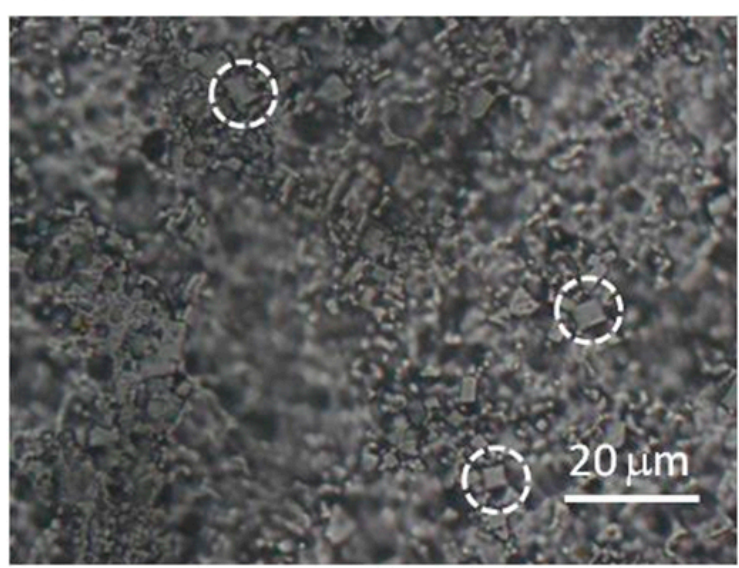

(b)

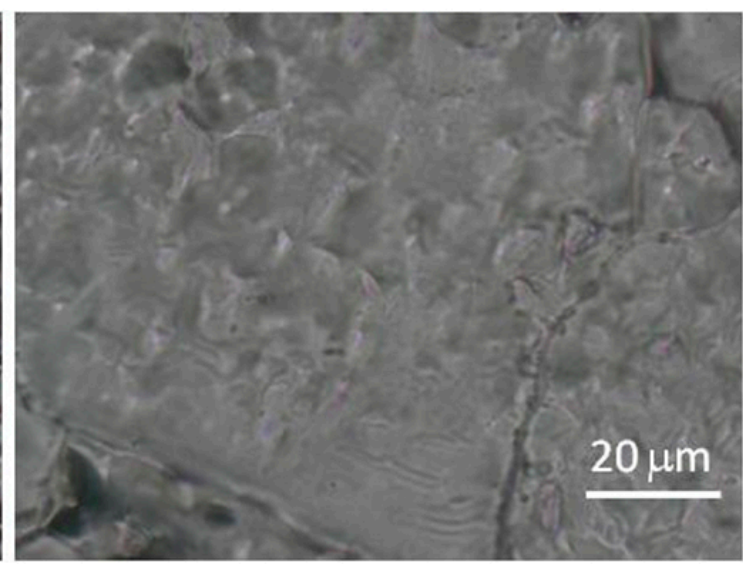

Figure 4. Micrographs of (a) M-CRL2 and (b) M-CRL3. White circles highlight crystalline inclusions. 
To further investigate the morphology of M-CRL3, atomic force microscopy (AFM) images of the sample were acquired in different region of the samples. Some of such images are compared with the ones of M-CRL1 film [13] in Figure 5. Particularly, $4 \mu \mathrm{m} \times 4 \mu \mathrm{m}$ (left) and $1 \mu \mathrm{m} \times 1 \mu \mathrm{m}$ (right) AFM images of M-CRL1 film are displayed in Figure 5a, while $4 \mu \mathrm{m} \times 4 \mu \mathrm{m}$ (left) and $1 \mu \mathrm{m} \times 1 \mu \mathrm{m}$ (right) AFM image of M-CRL3 film are shown in Figure 5b. The high magnification images were taken in the region marked with a white box in the low magnification images. From AFM images of M-CRL1, it is evident that the substrate was uniformly covered by nanometric aggregates that were due to lipase self-association. These aggregates had mean planar dimension of $40 \mathrm{~nm}$. Considering that lipase is a globular protein of approximately $5 \mathrm{~nm}$ in diameter, aggregates were composed of several lipase globules.

Figure 5b shows a different morphology for M-CRL3 film. As seen in the lower magnification picture, clusters were much smaller and concentrated in droplet-like regions of about $\leq 1 \mu \mathrm{m}$ in size, while at the nanometric level the compact structure of aggregates of $40 \mathrm{~nm}$ was not present, instead much smaller features were detected from the higher magnification picture, confirming a reduction of self-association of proteins as already suggested by FTIR analysis.

(a)
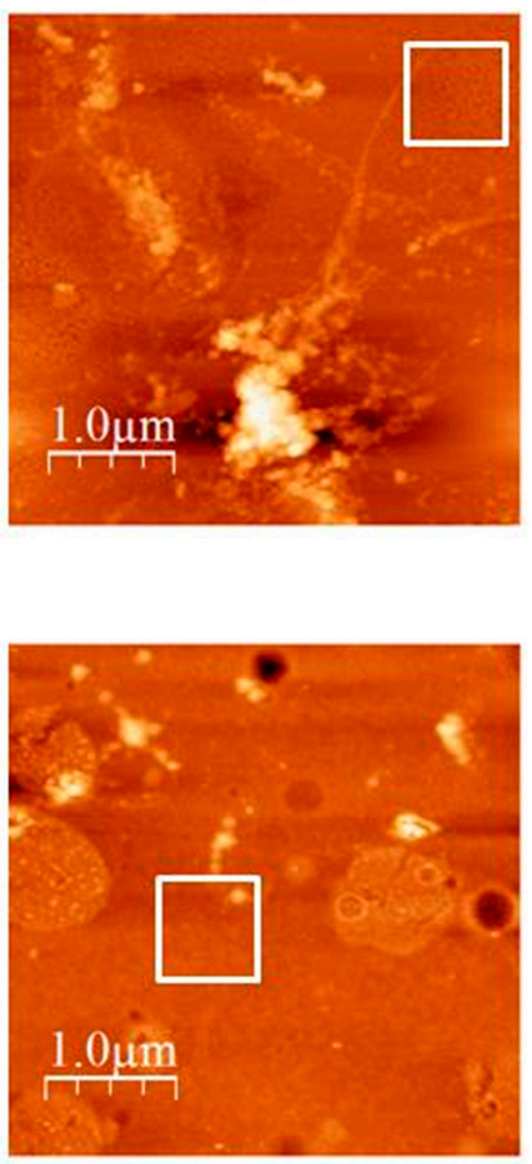

$163.5 \mathrm{~nm}$

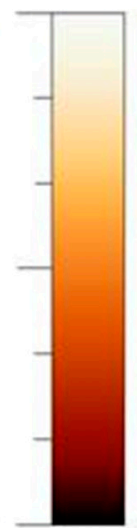

$0.00 \mathrm{~nm}$

$49.21 \mathrm{rm}$

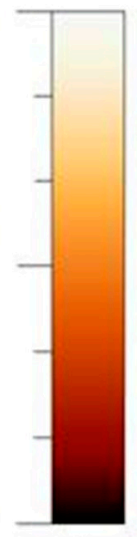

$0.00 \mathrm{~nm}$ (b)

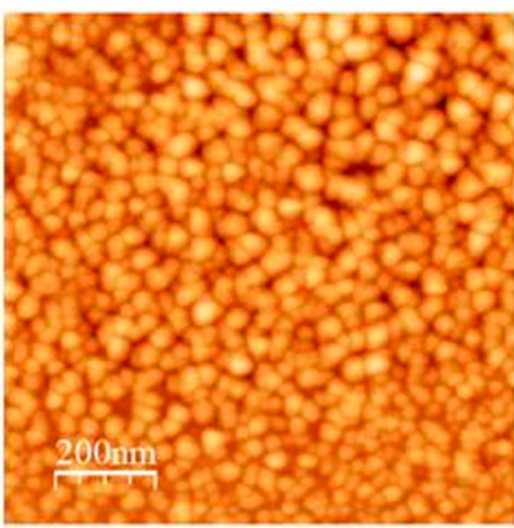

23.83 rum

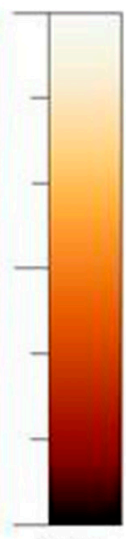

$0.00 \mathrm{~nm}$

$5.54 \mathrm{~nm}$
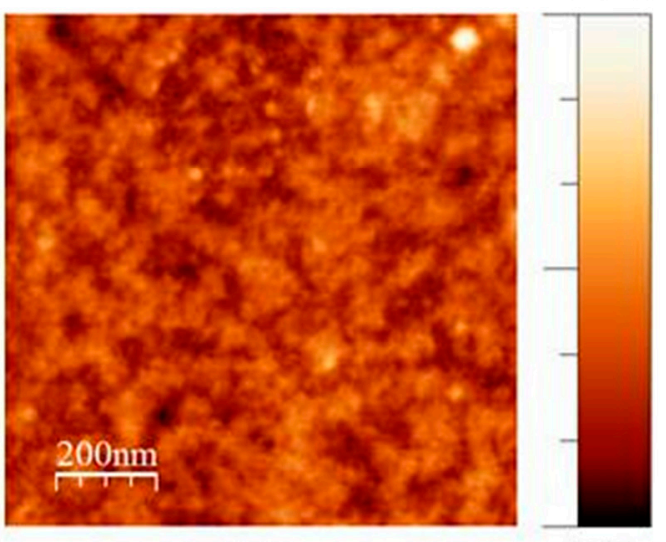

$0.00 \mathrm{rm}$

Figure 5. (a) $4 \mu \mathrm{m} \times 4 \mu \mathrm{m}$ (left) and $1 \mu \mathrm{m} \times 1 \mu \mathrm{m}$ (right) atomic force microscopy (AFM) images of M-CRL3 film; (b) $4 \mu \mathrm{m} \times 4 \mu \mathrm{m}$ (left) and $1 \mu \mathrm{m} \times 1 \mu \mathrm{m}$ (right) AFM image of M-CRL1 film. The white boxes indicate the regions where the magnification was performed.

Preliminary tests of the deposited lipase samples were performed by transesterification reaction carried out between soybean oil and isopropyl alcohol using reverse phase thin layer chromatography (RP-TLC) to identify the reaction products. In Figure 6 the chromatograms of the three samples 
(M-CRL1 in Figure 6c, M-CRL2 in Figure 6d and M-CRL3 in Figure 6e) are compared with that obtained using $1 \mathrm{mg}$ (Figure 6b) of free CRL as catalyst. The amount of $1 \mathrm{mg}$ was chosen since this was the order of magnitude of the amount of lipase deposited by MAPLE. For the sake of clarity, the chromatogram of unreacted oil (Figure 6a) and that obtained using $15 \mathrm{mg}$ of free CRL as catalyst (Figure 6f) are also reported. The amount of $15 \mathrm{mg}$ was chosen to clearly show the action of lipase.

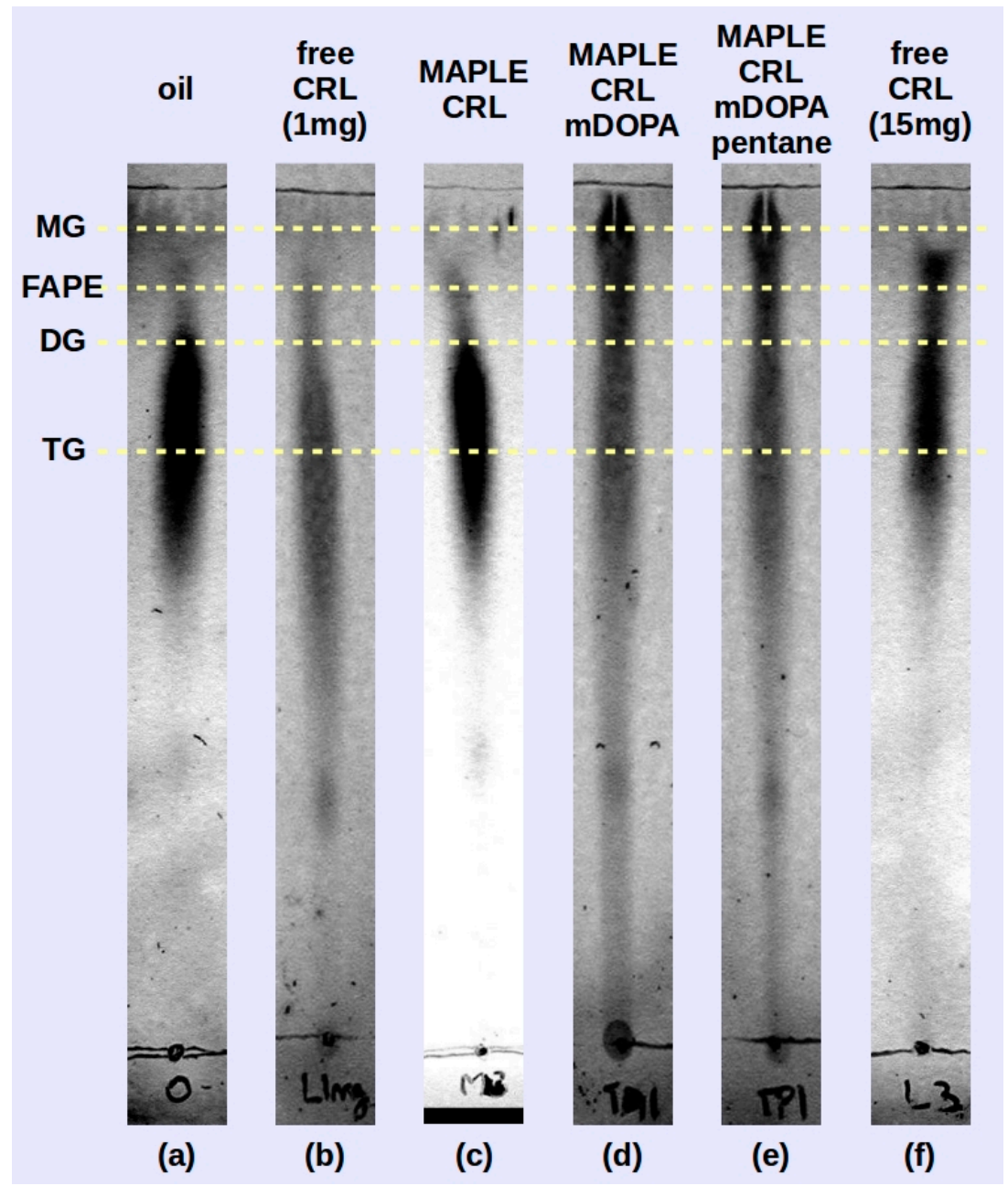

Figure 6. Thin layer chromatography (TLC) of transesterification products obtained the MAPLE deposited lipase M-CRL1 (c), M-CRL2 (d) and M-CRL3 (e) as biocatalysts are compared to the chromatogram of the unreacted oil (a) and that obtained using $1 \mathrm{mg}(\mathbf{b})$ and $15 \mathrm{mg}$ (f) of free-CRL as biocatalyst.

On the RP-TLC plate, the oil chromatogram shown in Figure 6a appeared elongated due to the variation in saturation and chain length of the component fatty acids [54]. For the reacted mixtures, the order of retention followed the polarity of the components: monoglycerides (MG) exhibited the least retention, followed by fatty acid propyl esters (FAPE), diglycerides (DG), and residual oil (TG, triglycerides) [53]. The RP-TLC results obtained using M-CRL1 as biocatalyst confirmed the data obtained with GC-MS analysis carried out in a previous study [21], allowing to identify peaks belonging to isopropyl esters of the most abundant fatty acid components of soybean oil, indicating that MAPLE deposited CRL preserved its functional role.

In the reacted mixture obtained using M-CRL2 (MAPLE deposited CRL with m-DOPA addition) and M-CRL3 (MAPLE deposited CRL with m-DOPA and pentane addition) lipase there was a higher quantity of MG and DG and a much lower quantity of FAPE with respect to the reaction mixture 
obtained with free-CRL. This occurrence appears unusual since CRL is a non-specific lipase, and in this kind of biocatalysts the reaction intermediates MG and DG do not accumulate since they react faster than the TG [55]. Actually, comparison of TLC analysis performed on the reaction mixture obtained using $1 \mathrm{mg}$ (Figure 6b) and $15 \mathrm{mg}$ (Figure $6 \mathrm{~b}$ ) of free-CRL shows that despite the smaller quantity of FAPE obtained, reaction intermediates DG and MG were not produced. We hypothesize that the higher production of MG and DG is due to the conformational changes induced in the lipase during the MAPLE process and evidenced by the FTIR analysis. Nevertheless, the presence of $\mathrm{KBr}$ as immobilization support is also important, since the presence of a salt can lead to the formation of fatty acid salts, which in turn may lead to enzyme inhibition through conformational changes induced by the electrostatic interaction between the anionic headgroup and sites of opposite charge on the protein [56].

\section{Materials and Methods}

Lipase from Candida rugosa type VII (Sigma) with activity $\geq 700 \mathrm{U} / \mathrm{mg}$ solid (One unit U hydrolyzes 1.0 microequivalent of fatty acid from a triglyceride in $1 \mathrm{hr}$ at $\mathrm{pH} 7.2$ at $37{ }^{\circ} \mathrm{C}$ ), and methyl-DOPA hemihydrate (Fluka) were acquired from Sigma-Aldrich (Milan, Italy). The composition of the lyophilizate is not specified, but it could contain surfactants, i.e., potassium sorbate [55], that can facilitate the emulsion formation. Deionized water was used to prepare MAPLE target solutions at $\mathrm{pH}=7$. All other solvents and compounds used were analytical grade from Sigma-Aldrich. Soybean oil was purchased in the local market. The MAPLE targets were prepared by dissolving the appropriate quantity of lipase in water (M-CRL1, $0.2 \mathrm{wt} \%$ of lipase), then adding the required amount of m-DOPA (M-CLR2, 0.18 wt \% of lipase and $0.2 \mathrm{wt} \%$ of m-DOPA) and of pentane (M-CLR3 0.18 wt \% of lipase and $0.2 \mathrm{wt} \%$ of $\mathrm{m}$-DOPA and $0.5 \% v / v$ of pentane).

A schematic of the MAPLE process is reported in Figure 7.

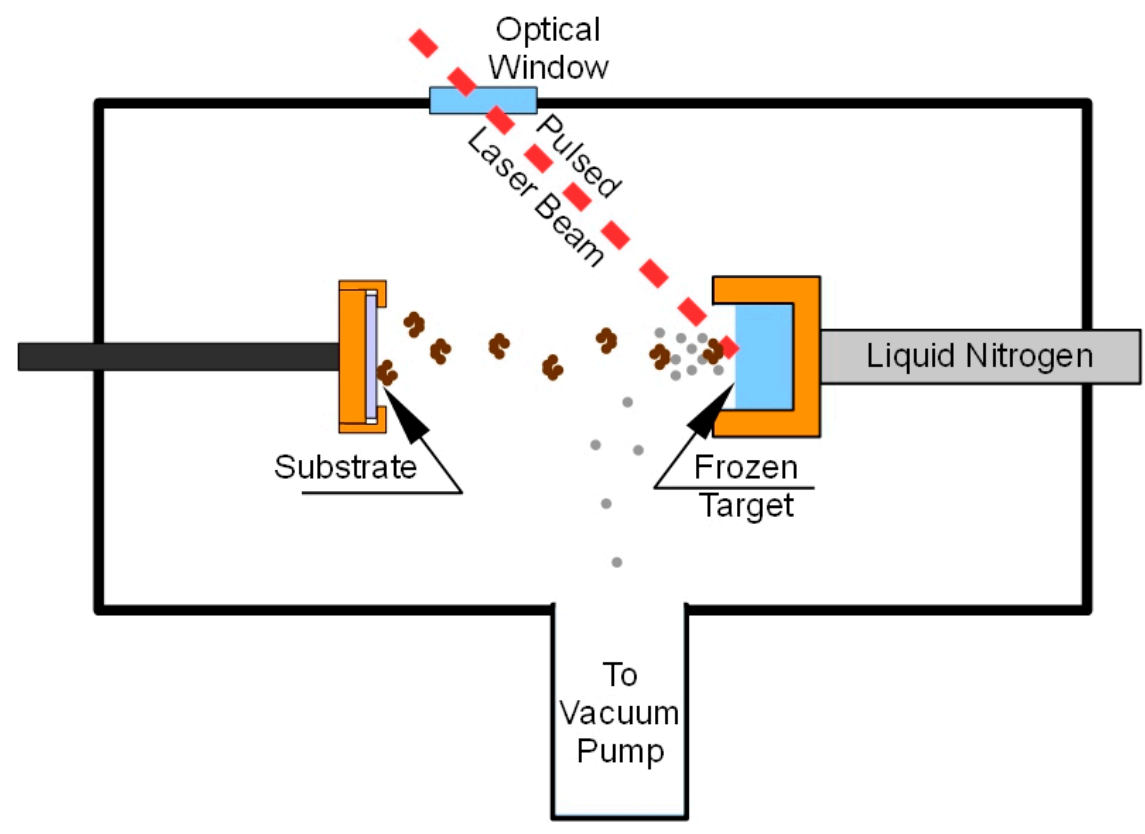

Figure 7. MAPLE deposition system.

About $2 \mathrm{~mL}$ of the target solution were placed into the target holder and frozen by thermal contact with liquid nitrogen $\left(-123^{\circ} \mathrm{C}\right)$. The deposition chamber was evacuated $\left(10^{-4} \mathrm{~Pa}\right)$, and afterward, the Nd:YAG pulsed laser was switched on to start the deposition. The target holder was moved by a computer controlled mechanical system so that the laser beam scanned an area of about $1.5 \mathrm{~cm}^{2}$ in order to prevent local overheating and drilling of the target. Lipase films were deposited on $\mathrm{KBr}$ pellets of 
$13 \mathrm{~mm}$ diameter in order to perform FTIR analysis. FTIR spectra were recorded, in the $4000-400 \mathrm{~cm}^{-1}$ range, using a spectrometer (Nicolet 5700, Thermo Fisher Scientific, Rodano, Italy) equipped with a DTGS KBr (deuterated triglycine sulphate with potassium bromide windows) detector. A spectral resolution of $2 \mathrm{~cm}^{-1}$ was chosen and each spectrum represents an average of 64 scans, corrected for the spectrum of the blank KBr pellet. For comparison, spectra were acquired also for lyophilized unprocessed lipase (free-CRL). Then, $4.0 \mathrm{mg}$ of lyophilized lipase were mixed with $196 \mathrm{mg}$ of $\mathrm{KBr}$ and pressed into pellets. The salt was previously dried at $100{ }^{\circ} \mathrm{C}$ for $24 \mathrm{~h}$ in order to eliminate the interference of water in the spectra.

The curve fitting of the amide I band was performed with curve-fit procedure of GRAMS/32, after smoothing and baseline subtraction. All spectra were analyzed by the second derivative method to determine the number of peaks and the peak positions to use as input parameters of the fitting. The second derivative spectra were obtained following the Savitsky-Golay method after a binomial 5 points smoothing of the spectrum followed by a baseline correction. The amide I band was analyzed in terms of a linear combination of spectral components identified in the second-derivative spectrum. Those components were approximated by Gaussian functions whose peak positions, widths and intensities were adjusted iteratively in the curve-fitting procedure. The initial full width at half height (FWHH) was $12 \mathrm{~cm}^{-1}$.

Images of the deposited CRL films on $\mathrm{KBr}$ substrate were obtained by means of an Olympus microscope with $100 \times$ magnification, using a micrometric slide to quantify the size of the aggregates formed in the process.

The typical sample morphology was determined by atomic force microscopy (AFM) analysis of deposits obtained onto KBr substrates. The analysis was performed by means of a Nanoscope IIIa AFM (Veeco Instruments Inc., Santa Barbara, CA, USA) operating in tapping mode (scan size and rate of $1 \mu \mathrm{m}$ and $1 \mathrm{~Hz}$, respectively) and equipped with a silicon tip having nominal curvature radius of about $5 \mathrm{~nm}$.

In order to assess the ability of the deposited lipase to perform their catalytic role, transesterification reaction were carried out between soybean oil and isopropyl alcohol, using the surfactant span $80^{\circledR}$ to emulsify the reactants. The reaction batches were prepared as follows: $0.043 \mathrm{~g}$ of Span $80^{\circledR}$ were added to $1.7 \mathrm{~g}$ of soybean oil under stirring. Once the surfactant was dissolved, $0.7 \mathrm{mg}$ of isopropyl alcohol were poured drop by drop in the solution, resulting in a slight opalescence (emulsion formation). To this reaction batches, CRL was added either in the free (1 mg and $15 \mathrm{mg}$ ) or in the immobilized form. The reaction mixtures were kept under stirring ( $200 \mathrm{rpm})$ for $24 \mathrm{~h}$ at $25^{\circ} \mathrm{C}$. The reaction products were qualitatively characterized by reverse phase thin layer chromatography (RP-TLC), using precoated TLC glass plates RP-18 (silica gel C18 layer of $0.25 \mathrm{~mm}$, Macherey-Nagel (Düren, Germany) $5 \mathrm{~cm} \times 20 \mathrm{~cm}$ in size as stationary phase and a solution of acetonitrile-ethylacetate 2.5:1 as mobile phase. The chromatograms were detected by spraying sulphuric acid $4 \mathrm{~N}$ on the chromatographic plates and heating them at $150{ }^{\circ} \mathrm{C}$.

\section{Conclusions}

Candida rugosa Lipase (CRL) was deposited by MAPLE tailoring the target composition in order to minimize the conformational modification observed during the process. In particular, a phenomenon of unfolding/aggregation was evidenced. Experimental results evidenced that unfolding/aggregation induced by MAPLE process can be minimized by tailoring the target matrix.

FTIR analysis was performed to investigate the conformational changes that the enzyme underwent during the deposition process. From the deconvolution of amide I band of the samples, it resulted that in M-CRL1 sample (water matrix), the content of intramolecular aggregates was $27.8 \%$, but it fell at $19.6 \%$ in M-CRL2 sample (water/m-DOPA matrix), indicating that the addition of the amino acid m-DOPA was able to prevent aggregation. From the analysis of amide $\mathrm{A}$ band, the percentage of unfolding in M-CRL2 is 65\%, even higher than in M-CRL1, while it became $42 \%$ in M-CRL3 (water/m-DOPA/pentane matrix), indicating that the addition of pentane to form a microemulsion 
was effective for preventing unfolding. All MAPLE deposited samples showed catalytic ability, but reaction privileged MG and DG products differently with respect to free-CRL, which can be due to the MAPLE induced conformational modification of the deposited lipases together with the presence of inhibitors (fatty acid salts due to the presence of $\mathrm{KBr}$ as support material) or restraints to conformational changes in the enzyme due to immobilization. The addition of an apolar solvent to the MAPLE target attenuated the conformational alteration occurring during MAPLE process, which represents a feasible way to maintain unaltered the conformation of the enzyme during the MAPLE deposition.

Acknowledgments: The research presented in this paper didn't received any funding. Costs for Open Access publication have been covered by Dipartimento di Fisica "Ettore Pancini", Università di Napoli "Federico II".

Author Contributions: F. Bloisi and L. Vicari carried out MAPLE depositions. A. Aronne and A. Costantini performed FTIR and data analysis. G. Ausanio is responsible for AFM measurements and G. Perretta carried out TLC. V. Califano wrote the paper and contributed in all experimental measurements and data elaboration.

Conflicts of Interest: The authors declare no conflict of interest.

\section{References}

1. Nielsen, P.M.; Brask, J.; Fjerbaek, L. Enzymatic biodiesel production: Technical and economical considerations. Eur. J. Lipid Sci. Technol. 2008, 110, 692-700. [CrossRef]

2. Sheldon, R.A. Enzyme immobilization: The quest for optimum performance. Adv. Synth. Catal. 2007, 349, 1289-1307. [CrossRef]

3. Jesionowski, T.; Zdarta, J.; Krajewska, B. Enzyme immobilization by adsorption: A review. Adsorption 2014, 20, 801-821. [CrossRef]

4. Secundo, F. Conformational changes of enzymes upon immobilization. Chem. Soc. Rev. 2013, 42, 6250-6261. [CrossRef] [PubMed]

5. Knêzevíc, Z.D.; Šiler-Marinkovíc, S.S.; Mojovíc, L.V. Immobilized lipases as practical catalysts. Acta Period. Technol. 2004, 35, 151-164. [CrossRef]

6. Pang, J.; Zhou, G.; Liu, R.; Li, T. Esterification of oleic acid with methanol by immobilized lipase on wrinkled silica nanoparticles with highly ordered, radially oriented mesochannels. Mater. Sci. Eng. C 2016, 59, 35-42. [CrossRef] [PubMed]

7. Mateo, C.; Palomo, J.M.; Fernandez-Lorente, G.; Guisan, M.J.; Fernandez-Lafuente, R. Improvement of enzyme activity, stability and selectivity via immobilization techniques. Enzym. Microb. Technol. 2007, 40, 1451-1463. [CrossRef]

8. Dwevedi, A. Enzyme Immobilization: Avances in Industry, Agriculture, Medicine, and the Environment; Springer: Basel, Switzerland, 2016. [CrossRef]

9. Sellinger, A.T.; Leveugle, E.; Gogick, K.; Peman, G.; Zhigilei, L.V.; Fitz-Gerald, J.M. Ejection of matrix-polymer clusters in matrix assisted laser evaporation: Experimental observations. J. Phys. Conf. Ser. 2007, 59, 314-317. [CrossRef]

10. Esenaliev, R.O.; Karabutov, A.A.; Podymova, N.B.; Letokhov, V.S. Laser ablation of aqueous solutions with spatially homogeneous and heterogeneous absorption. Appl. Phys. B Lasers Opt. 1994, 59, 73-81. [CrossRef]

11. Shepard, K.B.; Priestley, R.D. MAPLE deposition of macromolecules. Macromol. Chem. Phys. 2013, 214, 862-870. [CrossRef]

12. Cristescu, R.; Mihaiescu, D.; Socol, G.; Stamatin, I.; Mihailescu, I.N.; Chrisey, D.B. Deposition of biopolymer thin films by matrix assisted pulsed laser evaporation. Appl. Phys. A Mater. Sci. Process. 2004, 79, 1023-1026. [CrossRef]

13. Stamatin, L.; Cristescu, R.; Socol, G.; Moldovan, A.; Mihaiescu, D.; Stamatin, I.; Mihailescu, I.N.; Chrisey, D.B. Laser Deposition of fibrinogen blood proteins thin films by matrix assisted pulsed laser evaporation. Appl. Surf. Sci. 2005, 248, 422-427. [CrossRef]

14. Ringeisen, B.R.; Callahan, J.; Wu, P.K.; Piqué, A.; Spargo, B.; McGill, R.A.; Bucaro, M.; Kim, H.; Bubb, D.M.; Chrisey, D.B. Novel laser-based deposition of active protein thin films. Langmuir 2001, 17, 3472-3479. [CrossRef]

15. Purice, A.; Schou, J.; Kingshott, P.; Pryds, N.; Dinescu, M. Characterization of lysozyme films produced by matrix assisted pulsed laser evaporation (MAPLE). Appl. Surf. Sci. 2007, 253, 6451-6455. [CrossRef] 
16. Schmid, R.D.; Verger, R. Lipases: Interfacial enzymes with attractive applications. Angew. Chem. Int. Ed. 1998, 37, 1609-1633. [CrossRef]

17. De María, P.D.; Sánchez-Montero, J.M.; Sinisterra, J.V.; Alcántara, A.R. Understanding Candida rugosa lipases: An overview. Biotechnol. Adv. 2006, 24, 180-196. [CrossRef] [PubMed]

18. Blanco, R.M.; Terreros, P.; Fernández-Pérez, M.; Otero, C.; Díaz-González, G. Functionalization of mesoporous silica for lipase immobilization. J. Mol. Catal. B 2004, 30, 83-93. [CrossRef]

19. Bastida, A.; Sabuquillo, P.; Armisen, P.; Fernández-Lafuente, R.; Huguet, J.; Guísan, J.M. A single step purification, immobilization, and hyperactivation of lipases via interfacial adsorption on strongly hydrophobic supports. Biotechnol. Bioeng. 1998, 58, 486-493. [CrossRef]

20. Baron, A.M.; Barouh, N.; Barea, B.; Villeneuve, P.; Mitchell, D.A.; Krieger, N. Transesterificazione of castor oil in a solvent-free medium using the lipase from Burkholderia cepacia LTEB11 immobilized on a hydrophobic support. Fuel 2014, 117, 458-462. [CrossRef]

21. Aronne, A.; Ausanio, G.; Bloisi, F.; Calabria, R.; Califano, V.; Fanelli, E.; Massoli, P.; Vicari, L.R.M. Structural characterization of MAPLE deposited lipase biofilm. Appl. Surf. Sci. 2014, 320, 524-530. [CrossRef]

22. Manoel, E.A.; dos Santos, J.C.S.; Freire, D.M.G.; Rueda, N.; Fernandez-Lafuente, R. Immobilization of lipases on hydrophobic supports involves the openform of the enzyme. Enzym. Microb. Technol. 2015, 71, 53-57. [CrossRef] [PubMed]

23. Dalsin, J.L.; Messersmith, P.B. Bioinspired antifouling polymers. Mater. Today 2005, 9, 38-46. [CrossRef]

24. Califano, V.; Bloisi, F.; Vicari, L.R.M.; Colombi, P.; Bontempi, E.; Depero, L.E. MAPLE deposition of biomaterial multilayers. Appl. Surf. Sci. 2008, 254, 7143-7148. [CrossRef]

25. Tian, F.; Middaugh, C.R.; Offerdahl, T.; Munson, E.; Sane, S.; Rytting, J.H. Spectroscopic evaluation of the stabilization of humanized monoclonal antibodies in amino acid formulations. Int. J. Pharm. 2007, 335, $20-31$. [CrossRef] [PubMed]

26. Li, Y.; Liu, H.; Wang, T.; Qin, M.; Cao, Y.; Wang, W. Single-molecule force spectroscopy reveals multiple binding modes between DOPA and different rutile surfaces. Chem. Phys. Chem. 2016, 17, 1-5. [CrossRef] [PubMed]

27. Gottlieb, A.J.; Wurzel, H.A. Protein-quinone interaction: In vitro induction of indirect antiglobulin reactions with methyldopa. Blood 1974, 43, 85-97. [PubMed]

28. Foresti, M.L.; Ferreira, M.L. Frequent analytical/experimental problems in lipase-mediated synthesis in solvent-free systems and how to avoid them. Anal. Bioanal. Chem. 2005, 38, 1408-1425. [CrossRef] [PubMed]

29. Greer, J.A. Design challenges for matrix assisted pulsed laser evaporation and infrared resonant laser evaporation equipment. Appl. Phys. A Mater. Sci. Process. 2011, 105, 661-671. [CrossRef]

30. Stenberg, B.; Viscarra Rossel, R.A.; Mouazen, A.M.; Wetterlind, J. Advances in Agronomy; Sparks, D.L., Ed.; Academic Press: San Diego, CA, USA, 2010; pp. 163-215.

31. Maçzyński, A.; Wiśniewska-Gocłowska, B.; Góral, M. Recommended liquid-liquid equilibrium data. Part 1. Binary alkane-water systems. J. Phys. Chem. Ref. Data 2004, 33, 549-577. [CrossRef]

32. Flanagan, J.; Singh, H. Microemulsions: A potential delivery system for bioactives in food. Crit. Rev. Food Sci. Nutr. 2006, 46, 211-237. [CrossRef] [PubMed]

33. Reis, P.; Holmberg, K.; Watzke, H.; Leser, M.E.; Miller, R. Lipases at interfaces: A review. Adv. Colloid Interface Sci. 2009, 147-148, 237-250. [CrossRef] [PubMed]

34. Palomo, J.M.; Fuentes, M.; Fernández-Lorente, G.; Mateo, C.; Guisan, J.M.; Fernaández-Lafuente, R. General trend of lipase to self-assemble giving bimolecular aggregates greatly modifies the enzyme functionality. Biomacromolecules 2003, 4, 1-6. [CrossRef] [PubMed]

35. Cramp, G.L.; Docking, A.M.; Ghosh, S.; Coupland, J.N. On the stability of oil-in-water emulsions to freezing. Food Hydrocoll. 2004, 18, 899-905. [CrossRef]

36. Arrondo, J.L.R.; Muga, A.; Castresana, J.; Goni, F.M. Quantitative studies of the structure of proteins in solution by Fourier-transform infrared spectroscopy. Prog. Biophys. Mol. Biol. 1993, 59, 23-56. [CrossRef]

37. Natalello, A.; Ami, D.; Brocca, S.; Lotti, M.; Doglia, S.M. Secondary structure, conformational stability and glycosylation of a recombinant Candida rugosa lipase studied by Fourier-transform infrared spectroscopy. Biochem. J. 2005, 385, 511-517. [CrossRef] [PubMed]

38. Ranaldi, S.; Belle, V.; Rodriguez, J.; Guigliarelli, B.; Sturgis, J.; Carriere, F.; Fournel, A. Lid opening and unfolding in human pancreatic lipase at low $\mathrm{pH}$ revealed by site-directed spin labeling EPR and FTIR spectroscopy. Biochemistry 2009, 48, 630-638. [CrossRef] [PubMed] 
39. Zhou, Z.; Inayat, A.; Schwieger, W.; Hartmann, M. Improved activity and stability of lipase immobilized in cage-like large pore mesoporous organosilicas. Microporous Mesoporous Mater. 2012, 154, 133-141. [CrossRef]

40. Sucharda-Sobczyk, A.; Siemion, I.Z.; Konopinska, D. Infrared spectroscopic investigations of tuftsin and its analogs. Eur. J. Biochem. 1979, 96, 131-139. [CrossRef] [PubMed]

41. Noinville, S.; Revault, M.; Baron, M.; Tiss, A.; Yapoudjian, S.; Ivanova, M.; Verger, R. Conformational changes and orientation of Humicola lanuginosa lipase on a solid hydrophobic surface: An in situ interface Fourier transform infrared-attenuated total reflection study. Biophys. J. 2002, 82, 2709-2719. [CrossRef]

42. Narayanan, P. Essential of Biophysics; New Age International: New Delhi, India, 2000; p. 219.

43. Van Stokkum, I.H.M.; Linsdell, H.; Hadden, J.M.; Hais, P.I.; Chapman, D.; Bloemendal, M. Temperatureinduced changes in protein structures studied by Fourier transform infrared spectroscopy and global analysis. Biochemistry 1995, 34, 10508-10518. [CrossRef] [PubMed]

44. Chronopoulou, L.; Kamel, G.; Sparago, C.; Bordi, F.; Lupi, S.; Diociaiuti, M.; Palocci, C. Structure-activity relationships of Candida rugosa lipase immobilized on polylactic acid nanoparticles. Soft Matter 2011, 7, 2653-2662. [CrossRef]

45. Grochulski, P.; Li, Y.; Schrag, J.D.; Cygler, M. Two conformational states of Candida rugosa lipase. Protein Sci. 1994, 3, 82-91. [CrossRef] [PubMed]

46. Souillac, P.O.; Middaugh, C.R.; Rytting, J.H. Investigation of protein/carbohydrate interactions in the dried state. 2. Diffuse reflectance FTIR studies. Int. J. Pharm. 2002, 235, 207-218. [CrossRef]

47. Bloisi, F.; Califano, V.; Perretta, G.; Nasti, L.; Aronne, A.; Di Girolamo, R.; Auriemma, F.; De Rosa, C.; Vicari, L.R. Lipase immobilization for catalytic applications obtained using fumed silica deposited with MAPLE technique. Appl. Surf. Sci. 2015, 374, 346-352. [CrossRef]

48. Barth, A. Infrared spectroscopy of proteins. Biochim. Biophys. Acta (BBA) Bioenerg. 2007, 1767, 1073-1101.

49. Pimentel, G.C.; McClellan, A.L. The Hydrogen Bond; W.H. Freeman: San Francisco, CA, USA, 1960; pp. 118-119. [CrossRef]

50. Gutiérrez-Llorente, A.; Horowitz, G.; Pérez-Casero, R.; Perriére, J.; Fave, J.L.; Yassar, A.; Sant, C. Growth of polyalkylthiophene films by matrix assisted pulsed laser evaporation. Org. Electron. 2004, 5, 29-34. [CrossRef]

51. Gupta, R.K.; Ghosh, K.; Kahol, P.K.; Yoon, J.; Guha, S. Pulsed laser thin film growth of di-octyl substituted polyfluorene and its co-polymers. Appl. Surf. Sci. 2008, 254, 7069-7073. [CrossRef]

52. Bubb, D.M.; Corgan, J.; Yi, S.Y.; Khan, M.; Hughes, L.; Gurudas, U.; Papantonakis, M.; McGill, R.A. An experimental investigation of inhomogeneities in resonant infrared matrix-assisted pulsed-laser deposited thin polymer films. Appl. Phys. A Mater. Sci. Process. 2010, 100, 523-531. [CrossRef]

53. Zhigilei, L.V.; Volkov, A.N.; Leveugle, E.; Tabetah, M. The effect of the target structure and composition on the ejection and transport of polymer molecules and carbon nanotubes in matrix-assisted pulsed laser evaporation. Appl. Phys. A Mater. Sci. Process. 2011, 10, 529-546. [CrossRef]

54. Wall, P.E. III $\backslash$ Triglycerides $\backslash$ Thin-Layer (Planar) Chromatography. In Encyclopedia of Separation Science; Wilson, I.D., Cooke, M., Poole, C.F., Eds.; Academic Press: London, UK, 2000; pp. 4412-4420.

55. Illanes, A. Enzyme Biocatalysis: Principles and Applications; Springer: Amsterdam, The Netherlands, 2008; p. 299.

56. Reis, P.; Miller, R.; Leser, M.; Watzke, H. Lipase-catalyzed reactions at interfaces of two-phase systems and microemulsions. Appl. Biochem. Biotechnol. 2009, 158, 706-721. [CrossRef] [PubMed]

Sample Availability: Samples of the compounds are available from the authors. 